\title{
Performance and predict the ball bearing faults using wavelet packet decomposition and ANFIS
}

\author{
Arun R. Pathiran ${ }^{1}$, K. Erikiananda ${ }^{2 *}$, T. Getachew ${ }^{3}$ and Haftom G. Gziabher ${ }^{4}$ \\ ${ }^{1,4}$ Department of Electrical Technology, Federal Technical and Vocational Education and Training Institute, Addis Ababa, ETHIOPIA \\ ${ }^{2 * 3}$ Department of Automotive Technology, Federal Technical and Vocational Education and Training Institute, Addis Ababa, ETHIOPIA \\ *Corresponding Author: e-mail: erikiananda@yahoo.co.in, Tel +251-116464455, Fax. +251-11-6465675
}

\begin{abstract}
Element bearings are widespread significant parts of rotary machinery in industries and their condition monitoring through fault detection and isolation methods are of superior interests to engineers. Condition monitoring could assist in attaining effective system maintenance and the automation processes. Nonetheless, despite the availability of diverse bearing fault detection methods, there is paucity of literature concerning the theoretical modelling of the bearing faults using mathematical representations. The principal goal of this communication is to build up an approach to predict ball bearing fault, including ball fault, outer race fault and inner race fault. The proposed method uses the vibration data collected from the rotating ball bearing and predicts the type of fault. The proposed method is based on wavelet decomposition method, PCA, ANFIS and SVM. The vibration data is decomposed into 3rd level wavelet components using wavelet packet decomposition; each wavelet component has been divided into several energy segments, these 3rd level wavelet components are reduced to lower level components using Principal Component Analysis (PCA). ANFIS algorithm is trained using the reduced feature set as input and the type of fault as output. The trained ANFIS algorithm is validated using another set of data. Support Vector Machine (SVM) has been used instead of ANFIS algorithm, the SVM based method gives more accurate prediction compared to that of ANFIS. The proposed method has been validated using the real-time data collected from the ball bearing setup. The validation results show that the proposed method exactly predicts the type of ball bearing fault. The real-time data validation results confirm the accuracy of the fault prediction method.
\end{abstract}

Keywords: Principal component analysis, support vector machine; ANFIS; bearing

DOI: http://dx.doi.org/10.4314/ijest.v11i2.3

\section{Introduction}

In the condition monitoring research and practice domain, judging the overall performance of rotary machinery may be regarded comprehensive if the dynamic performance of its rotary parts is incorporated in the evaluation scheme. However, determination in performance may be experienced due to the influence of over-usage and frictional forces, leading to component damage. For bearings, the occurrence of defects usually causes lessened efficiency, or worse, chronic damage to the machinery being considered. As a result, this places high premium on the effects to monitor progressive wear in bearings with the application of the diverse non-destructive know-how, with preference to vibration examination method and the application of modern signal processing schemes on the attained readings to aid supervisor diagnostic routes. Since bearing serves the purpose to lessen the friction the mating parts by disallowing physical interaction among them, the development of any fault or crack in the bearing will certainly limit the efficiency of the bearing, by implication, its influence on the output of the equipment. In the worse case, equipment breakdown may develop from it, and may even threaten the lives of workers associated with the machines. The idea is that there is necessity to change the faulty bearing by means of a superior one since the cost of bearing changes is extremely low when weighed against equipment shut down. Every bearing element has an outstanding feature of rotary defect frequency that is a function of the kinematic consideration. Knowledge of the bearing's rotational speed and geometry aid in the computation of this 
frequency, to give a value that is often less than $500 \mathrm{~Hz}$. With the occurrence of a particular defect on a bearing element such as a rough defect, there is a noticeable growth of the vibration thresholds and this is the principal reason to analyse using the frequencydomain scheme of vibration recordings, often conducted to establish the situation of bearings. It should be noted that several methods exists, which could be engaged to predict the bearing condition, such as vibration monitoring, current signature analysis, thermography and tribology.

Table 1 shows the failure mechanisms and the associated reasons for damage while Table 2 reveals the damages and the corresponding effects.

Table 1. Failure Mechanisms and Reasons for damage (Bhende et al., 2011)

\begin{tabular}{|l|l|}
\hline \multicolumn{1}{|c|}{ Failure Mechanisms } & \multicolumn{1}{c|}{ Reason for damage } \\
\hline Mechanical Damage & Permanent indentation created by rolling element overload \\
\hline Crack Damage & Manufacturing defect or operating stress due to overload \\
\hline Wear Damage & Gradual deterioration or abrasive particle entrained \\
\hline Insufficient lubrication & When lubrication condition becomes inadequate increases friction \\
\hline Corrosion & Humid ambient subjected to surface oxidation \\
\hline Fatigue damage & Material fatigue after certain running time \\
\hline
\end{tabular}

Table 2. Damages and corresponding effects

\begin{tabular}{|c|l|c|c|c|c|c|}
\hline Sl.No & Method of analysis & Temperature & Pressure & Flow & Oil analysis & Vibration \\
\hline 1 & Out of balance & & & & & $x$ \\
\hline 2 & Misalignment & $x$ & & & & $x$ \\
\hline 3 & Bent shaft & $x$ & & & & $x$ \\
\hline 4 & Gear damage & & & & & $x$ \\
\hline 5 & Noise & & & & & $x$ \\
\hline 6 & Cracking & & & & $x$ & $x$ \\
\hline 7 & Ball bearing Damage & $x$ & & $x$ & $x$ & $x$ \\
\hline 8 & Mechanical rubbing & & $x$ & & \\
\hline
\end{tabular}

The proposed method is based on wavelet decomposition method, PCA, ANFIS and SVM. The performance of SVM and ANFIS algorithm is compared. It is found that SVM based prediction has higher accuracy compared to that of ANFIS.

\section{Literature Review}

The wavelet amplitude maps relating to the different gear health conditions are portioned into 6 sections and constant wavelet coefficients from ideal scales nourished specifically to the ANFIS as information tests. The outcomes exhibit that acoustic signs and ANFIS can viably be used to analyze the state of the gearbox (Anand and Singh, 2019). A wavelet packet denoising (WPD) procedure and an improved adaptive neuro-fuzzy inference system (ANFIS) based on Cauchy oscillation shuffled frog leaping algorithm (COSFLA).The wavelet packet denoising methodology is based on soft thresholding and Shannon entropy using a Db10 wavelet which is applied to remove the noise component from the measured apparent resistivity data (Jiang et al., 2018). A method for classification of fault and prediction of degradation of components and machines in manufacturing system, setup for the processing of the signals and collecting the data is explained in detail. The analysis is focused on the vibration signals collected from the sensors mounted on the machines for critical components monitoring (Zhang et al., 2013)

Condition-based maintenance (CBM) has attracted more attention and interest due to its advantages over the conventional breakdown-based or time-based maintenance. CBM of electrical machines such as motors is based on using data obtained by realtime condition monitoring, and fault detection and diagnosis to recommend an optimized maintenance. This paper presents an application of an Artificial Neural Network (ANN) for detecting a very small fault in a bearing shield of an induction motor. The experimental results show that the incipient fault can be efficiently detected. An alarm may be activated so that corrective actions are promptly taken before the detected fault manifests itself to be further serious failures (Liu et al., 2015). The use of c-SVC and nu-SVC models of support vector machine (SVM) with four kernel functions for classification of faults using statistical features extracted from vibration signals under good and faulty conditions of rotational mechanical system. Decision tree algorithm was used to select the prominent features. These features were given as inputs for training and testing the c-SVC and nu-SVC model of SVM and their fault classification accuracies were compared (Saimurugan et al., 2011). After several studies showed that the most important technique in predictive maintenance is vibration analysis as it gives clear indications regarding the condition of the machine in question, in addition the level of vibrations and the frequency at which these vibrations occur can serve in determining the exact location of the defect and possibly severity of such defect (Bhende et al., 2011). 
Principal Component Analysis (PCA), advantages of PCA, feature reduction procedure using PCA, step by step procedure of obtaining Principal component matrix from the raw data sets is studied (Sun et al., 2007). A survey of machine condition was monitoring and fault diagnosis using support vector machine (SVM). It attempts to summarize and review the recent research and developments of SVM in machine condition monitoring and diagnosis. Numerous methods have been developed based on intelligent systems such as artificial neural network, fuzzy expert system, condition-based reasoning, random forest, etc. (Li et al., 2006). The three datasets, namely, DBALL, DINN, and DOUT, are used to test the classification performance of statistical features under the same fault type but with different fault degrees. The nonlinearity of the ball fault is more complicated than the inner race and outer race faults, which necessitates the addition of more features (Zhu et al., 2012). The approach is accurate up to local first order approximations of the nonlinearities. It is shown to provide successful weight initialization for many data sets in the reduced number of inputs leads to faster training requiring far less iterations making the procedure suitable for on-line condition monitoring and diagnostics of machines (Samanta and Al-Balushi, 2003)

\section{Experimental Setup}

In this research, two experimental setups are used (Figures 1 and 2). One is used to obtain vibration signals for running of classifiers and other setup is for real time condition monitoring of the bearing. Vibration data acquired from the sensor is converted instantly into displacement of sensor; frequency drive is used to change the speed of the motor. Motor in turn rotates the shaft and the bearing, thus it controls the speed of the bearing. Change in the speed of the motor, condition of the bearing changes the vibration of the bearing. This results in the changes in the vibration data.
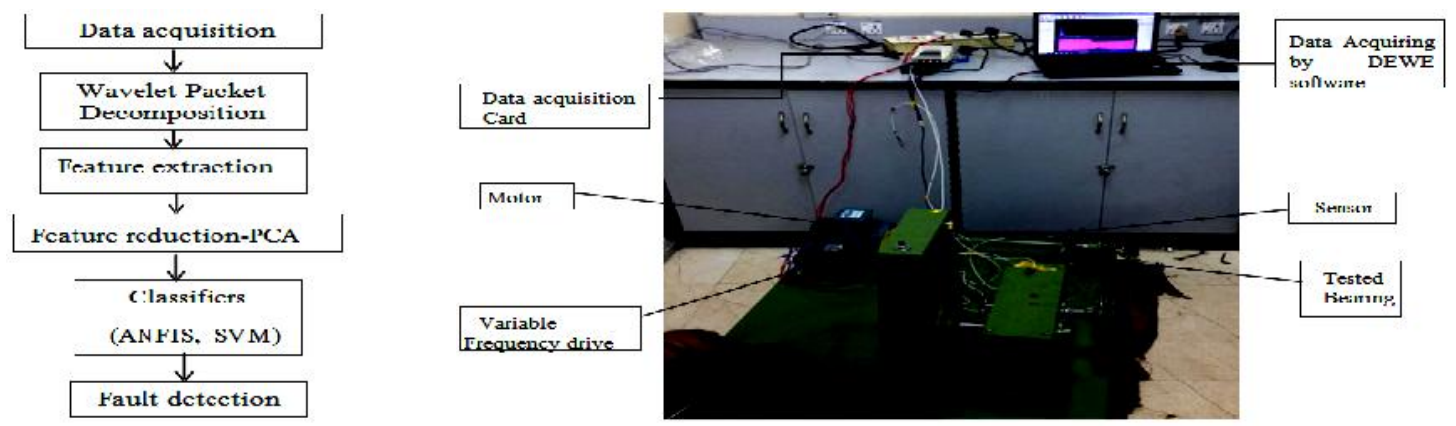

Figure 1. Flow chart of Fault detection system and Experimental setup

The Real time experiment setup differs from the training setup in such a way that the former has electronic components attached to the output of the sensor and the later has data acquisition card to convert from the vibration to displacement. Differences are listed below:

\begin{tabular}{|l|l|}
\hline $\begin{array}{l}\text { Proposed } \\
\text { Setup }\end{array}$ & $\begin{array}{l}\text { Conventional } \\
\text { Setup }\end{array}$ \\
\hline $\begin{array}{l}\text { Electronic } \\
\text { components } \\
\text { are present }\end{array}$ & $\begin{array}{l}\text { No electronic } \\
\text { components }\end{array}$ \\
\hline $\begin{array}{l}\text { No data } \\
\text { acquisition } \\
\text { card }\end{array}$ & $\begin{array}{l}\text { Data } \\
\text { acquisition } \\
\text { card is attached }\end{array}$ \\
\hline $\begin{array}{l}\text { Data is } \\
\text { collected } \\
\text { using Matlab }\end{array}$ & $\begin{array}{l}\text { Data is } \\
\text { collected using } \\
\text { DEWE 7.0 } \\
\text { software }\end{array}$ \\
\hline $\begin{array}{l}\text { ANFIS } \\
\text { output is } \\
\text { obtained } \\
\text { from Matlab }\end{array}$ & $\begin{array}{l}\text { Only storage of } \\
\text { data }\end{array}$ \\
\hline
\end{tabular}

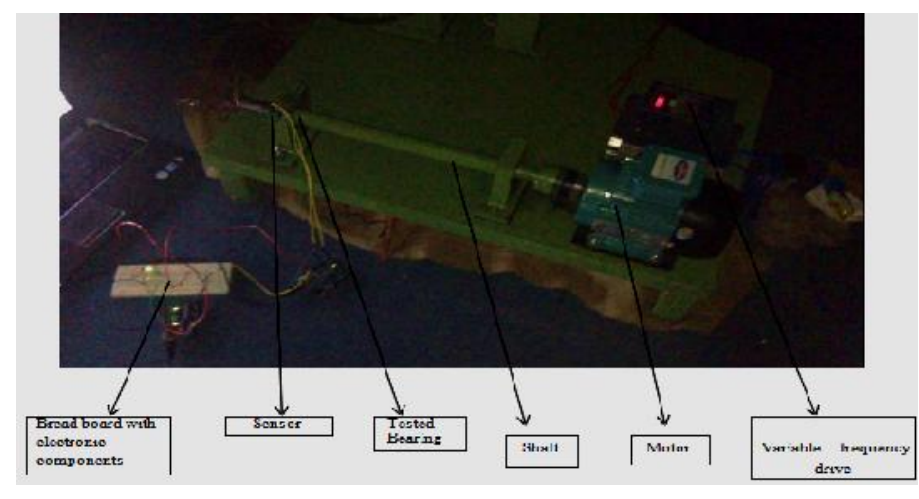

Figure 2. Proposed monitoring setup 
Many signal processing techniques have been proposed in literature for machinery fault diagnosis. In time domain analysis, a bearing fault is diagnosed with the help of some statistical indexes (e.g., RMS value, crest factor, or kurtosis) however, most of these monitoring indexes are sensitive to noise and operating conditions (Bhende et al., 2011). Frequency analysis may be the most fundamental approach for bearing fault detection. Bearing health conditions are assessed by examining the fault-related characteristic frequency components in the spectra or some associated expressions such as bi spectrum and cepstrum maps (Bhende et al., 2011). Frequency based techniques however, are unsuitable for the analysis of non-stationary signatures that are usually related to machinery defects (Bhende et al., 2011). Non-stationary or transient signals can be analyzed using timefrequency domain techniques such as short-time Fourier transform (STFT), Wigner-Ville distribution, or wavelet transform (WT). In fault diagnosis, the WT is more suitable than either the Wigner-Ville transform that contains some cross terms or the short-time FT that has a limited multi resolution solution (Bhende et al., 2011). According to signal decomposition paradigms, the WT can be performed by the continuous WT, discrete WT, and wavelet packet analysis and extended WT with post processing. Although a wavelet packet map can provide more information, its processing results are usually difficult to explain especially when the bearing operates under different load/speed operating conditions. Displacement data of the sensor from its mean position is stored in an excel sheet using DEWE software (Bhende et al., 2011). One of the simpler detection and diagnostic approaches is to analyze the measured vibration signal in the time domain. Whilst this can be as simple as visually looking at the vibration signal, other more sophisticated approaches can be used such as trending time domain statistical parameters (Bhende et al., 2011). An arduino is being used for acquisition of the values thus monitoring the condition of the bearing (Figure 3). For the transfer of high dimensional fault data into low dimensional fault data Principal Component Analysis (PCA) is used.
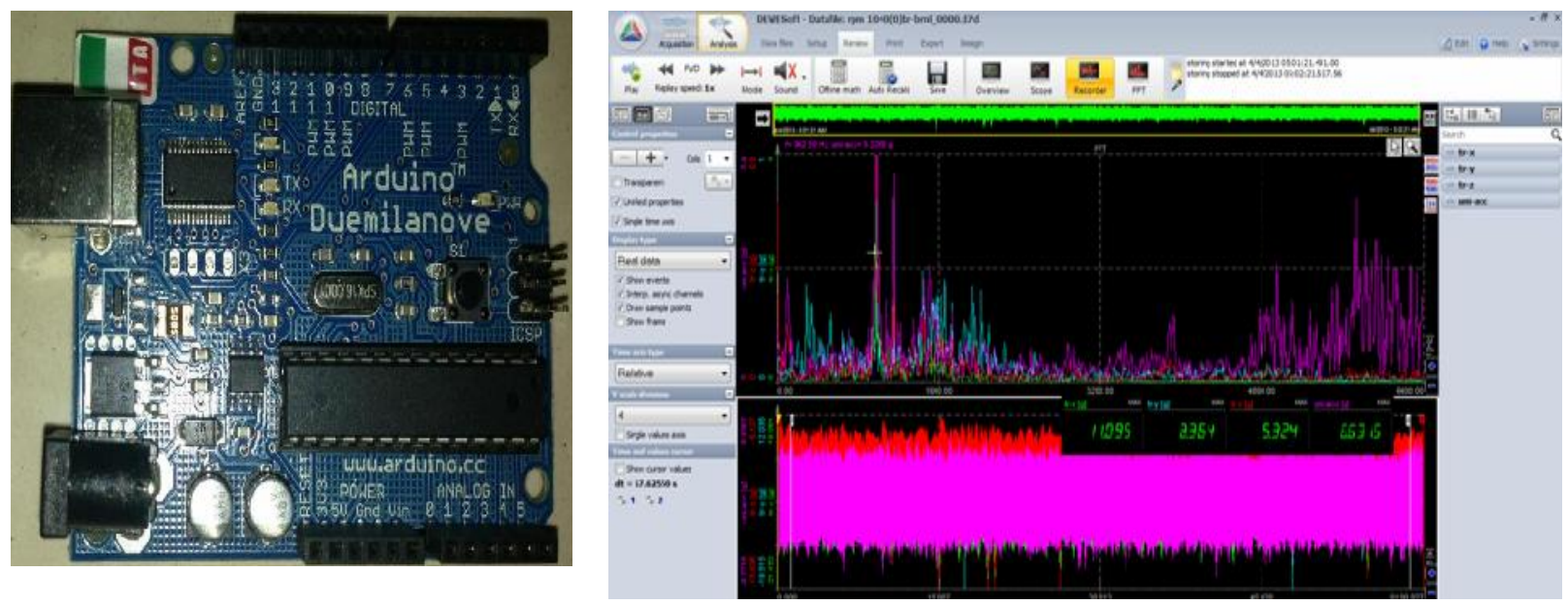

Figure 3. Arduino Board with Signal Processing Using DEWESoft

First step of vibrations measurement of the bearing is to collect the signals. The sensing element for collecting the signals will be accelerometer. The accelerometer gives a voltage reading that corresponds to the level of vibration. The analog signals given by the accelerometer are then collected by the Data Acquisition Card and transform them into digital signals so that it can read by an analyzing interface. The analyzing interface (computer software) is used to perform and use the analysis methods.

A number of transducer types exist for measuring machine vibration, including proximity probe, velocity transducers, accelerometers etc. The measurement of machine casing acceleration is the most common method used for bearing fault detection (Bhende et al., 2011) (Figure 4).

- Data Acquisition: This is normally achieved by mounting piezoelectric accelerometer externally on the machine casing, preferably near or on the bearing housing, or on the portion of the casing where relatively rigid connection exists between the bearing support and transducer. Piezoelectric sensors are less sensitive to temperature which is important since most machinery fault results in temperature increase. This will allow the bearing vibration to transmit readily through the structure to transducer. Accelerometers have the advantage of providing a wide dynamic range and a wide frequency range for vibration measurement. They have been found to be the most reliable, versatile and accurate vibration transducer available (Bhende et al., 2011).

- Sensor: used in this project for acquiring data is 3- axis accelerometer ADXL335 is a little, slim, depleted power, total 3axis accelerometer with signal conditioned voltage outputs. The product measures acceleration with a minimum full-scale range of $\pm 3 \mathrm{~g}$. It can measure the static acceleration of gravity in tilt-sensing applications, as well as dynamic acceleration resulting from motion, shock, or vibration. 

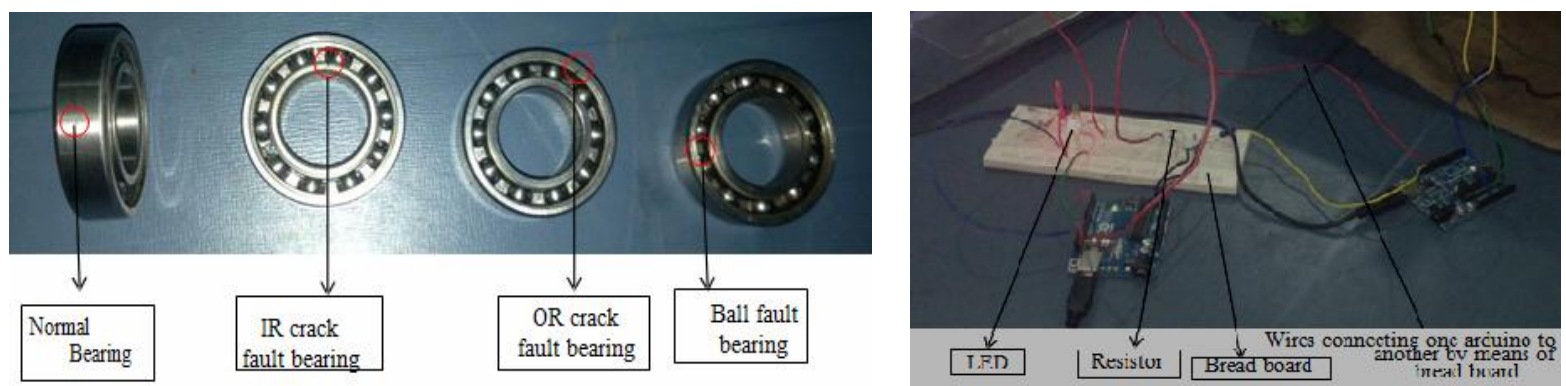

\section{Methodology}

Figure 4. Types of bearing faults and Signal Acquisition

In this research, two experimental setups are used. One is used to obtain vibration signals for running of classifiers. Additional details are provided in Table 3 and Figure 5.

Table 3. Damages and corresponding effects

\begin{tabular}{|c|c|}
\hline $\begin{array}{c}\text { DATA } \\
\text { ACQUISITION } \\
\end{array}$ & $\begin{array}{l}\text { Step-1: Displacement of the bearing from its rest position is determined by the } \\
\text { sensor and is stored in time domain variable. }\end{array}$ \\
\hline $\begin{array}{l}\downarrow \\
\text { Supervised } \\
\text { leaming }\end{array}$ & $\begin{array}{l}\text { Step-2: Frequency domain values for the data are calculated and are stored in } \\
\text { adjacent columns of the time domain values. These are stored in another } \\
\text { variable, say a. }\end{array}$ \\
\hline \begin{tabular}{ll}
\multicolumn{1}{l}{} & $\downarrow$ \\
$\begin{array}{l}\text { Frequency } \\
\text { Features }\end{array}$ & Domain \\
\end{tabular} & $\begin{array}{l}\text { Step-3: Covariance matrix for the fault by feature matrix is calculated in Matlab } \\
\text { using the keyword " } \operatorname{cov}(a) \text { " and is stored in separate variable, say b }\end{array}$ \\
\hline$\downarrow$ & Step-4: Eigen values and Eigen vectors for the covariant matrix are calculated. \\
\hline $\begin{array}{l}\text { Fault by feature } \\
\text { matix }\end{array}$ & $\begin{array}{l}\text { Since the output from the covariance matrix has the size of column size by } \\
\text { column size (column size of covariant matrix), it is possible to determine Eigen }\end{array}$ \\
\hline$\downarrow$ & $\begin{array}{l}\text { values and Eigen vectors directly as they will be calculated only for square } \\
\text { matrices. It is calculated in the Matlab by using syntax: }[\mathrm{V}, \mathrm{d}]=\text { eig (b) }\end{array}$ \\
\hline$\downarrow$ & Step-5: Sum of the Eigen values is calculate and is multiplied by a number less \\
\hline $\begin{array}{l}\text { Eigen values and } \\
\text { Eigen vector }\end{array}$ & than 1 to get preci \\
\hline$\downarrow$ & $\begin{array}{l}\text { Step-6: Using the precision parameter value Eigen values having less } \\
\text { significance are deleted. }\end{array}$ \\
\hline $\begin{array}{l}\text { Significant } \\
\text { values using } \\
\text { PCA }\end{array}$ & $\begin{array}{l}\text { Step-7: Deleted Eigen value positions are noted and Eigen vectors at the same } \\
\text { position are deleted. }\end{array}$ \\
\hline Feature reduction & Step-8: Now the remaining Eigen values are multiplied with the initial values to \\
\hline$\downarrow$ & numbers so that calculation time taken will be less which will be useful for \\
\hline $\begin{array}{l}\text { cipal Component } \\
\text { iix }\end{array}$ & \\
\hline
\end{tabular}

Inputs: $\mathrm{T}=$ Training Matrix, $\mathrm{C}=\mathrm{Group}$, test=Testing matrix 


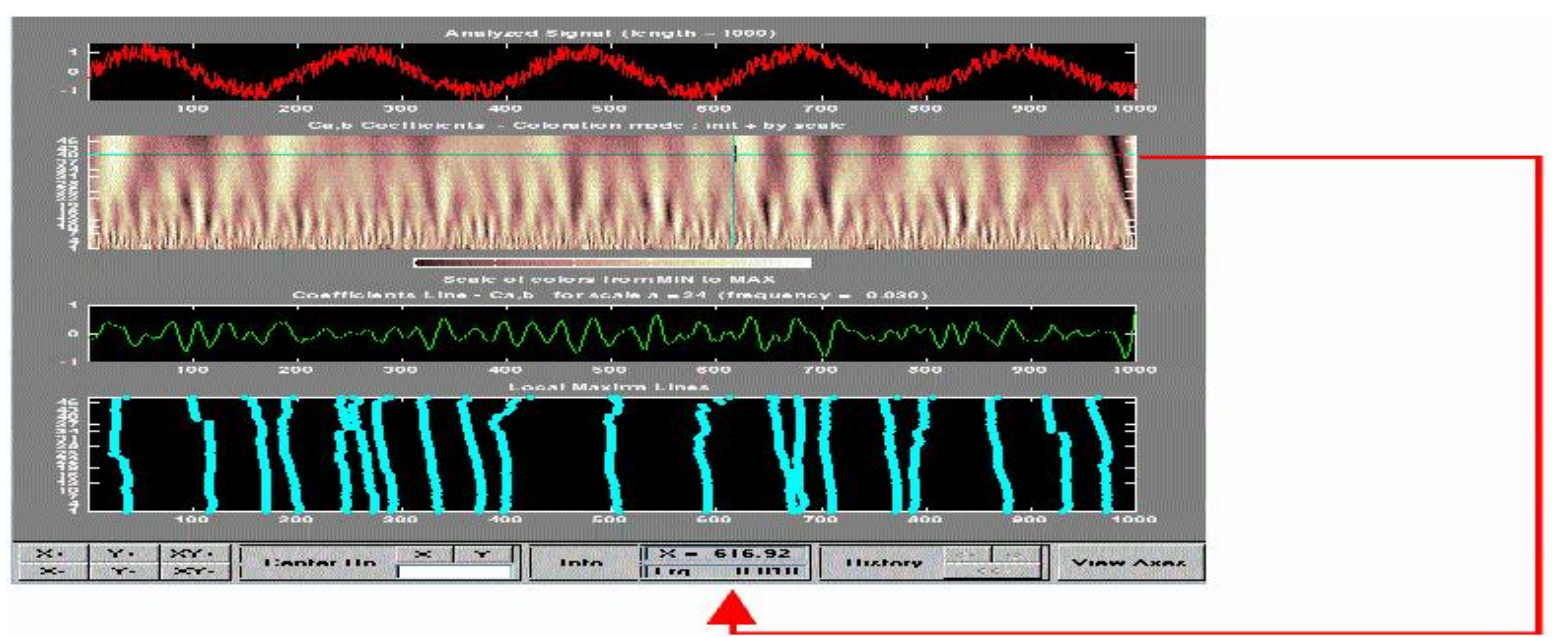

Figure 5. Wavelet analysis using Matlab

Outputs: itrfin=Resultant class (Group,USE ROW VECTOR MATRIX) to which tst set belongs:

\section{Pseudo Code:}

FOR tempind $:=1$ to number of training rows DO

$\mathrm{u}:=$ unique elements in class vector (classes)

IF number of classes $>2$ THEN

svmStruct $:=$ train SVM using rbf kernel classify the current row

\section{Results and Discussion}

The results obtained from the study are displayed in Figures 6 to 17 and Tables 4 to 14 .

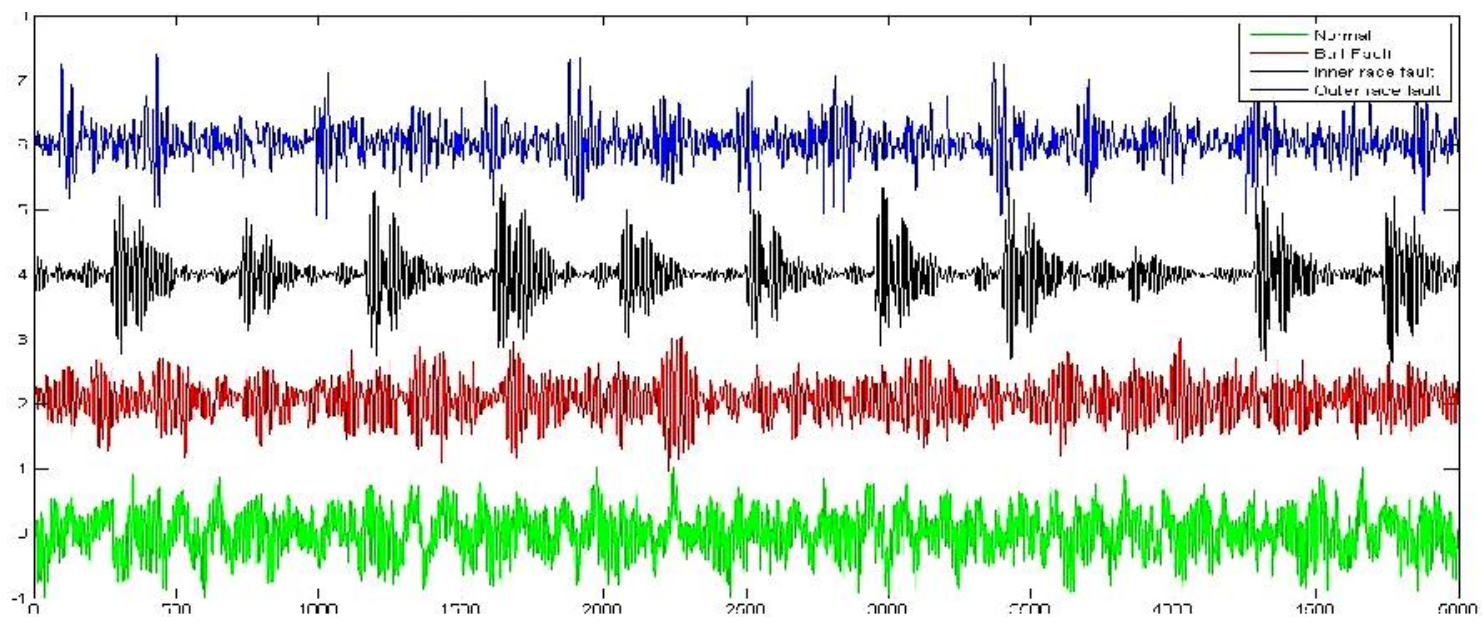

Figure 6. Raw signals 

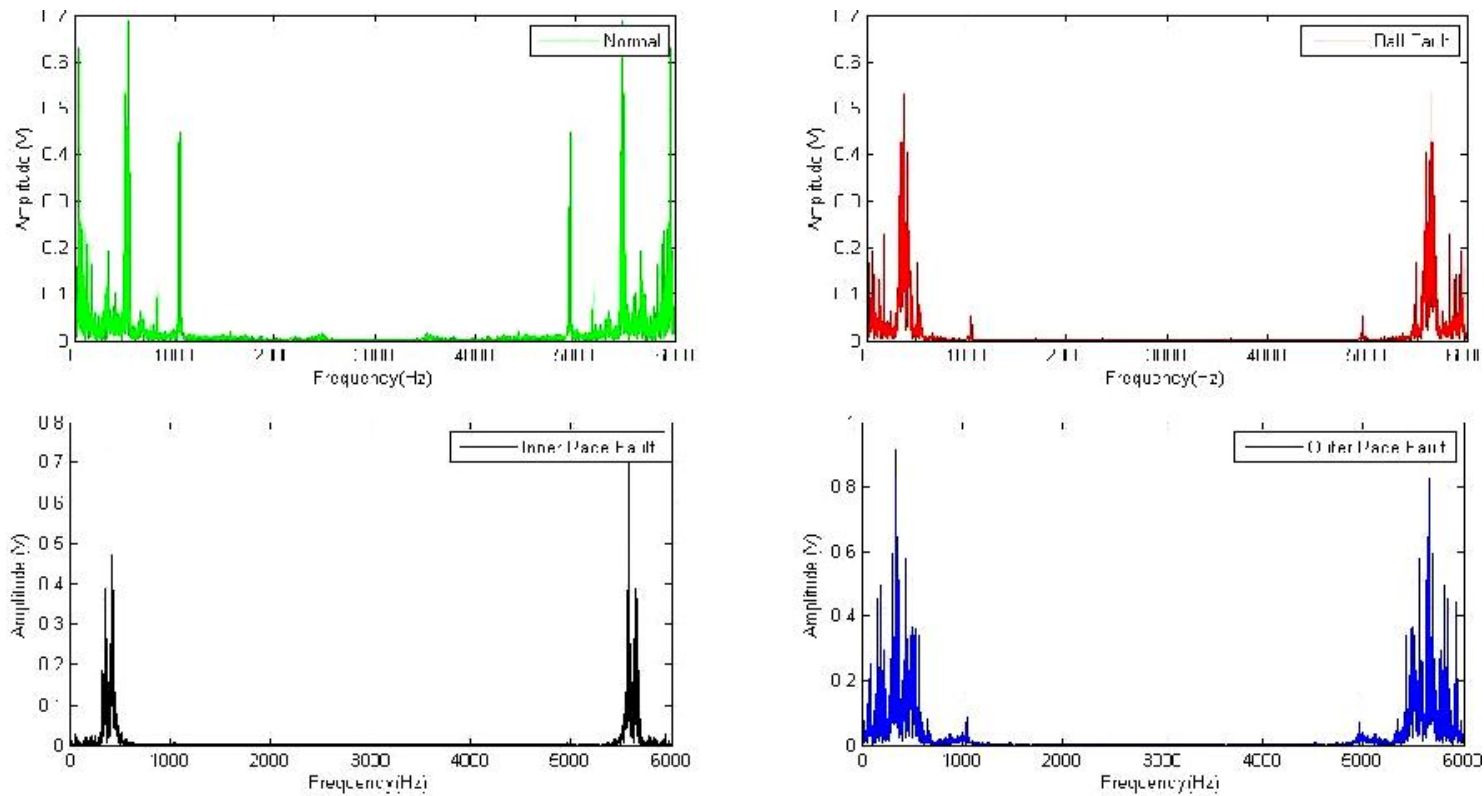

Figure 7. FFT of Raw signals

\begin{tabular}{|c|c|c|c|c|c|c|c|c|}
\hline & Mean & Variance & SMR & & & sk & Kurtosis & sFactor \\
\hline R.wearMin & 35.0608502 & 36744.2648 & 194.867588 & 194.867588 & 23823.6246 & 296228171 & $3.9299 \mathrm{E}+12$ & \\
\hline Max & 12.8978048 & 5556.41461 & 75.6486786 & 486786 & 7934.16441 & 11110135.8 & $4.8013 E+10$ & 3672 \\
\hline O.R.wearMin & 3881 & $41 \varepsilon$ & 740.1 & 9023 & 87394.2265 & 1.7 & +14 & 7046 \\
\hline O.R. & & & 702 & & & & & 719 \\
\hline Ballv & 17 & & 26 & 26 & 44 & & & 501 \\
\hline BallW & 58 & 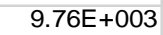 & 12 & 42 & 03 & & 10 & 933 \\
\hline R.crackMin & 625 & 176 & 423.8 & 423 & .18 & 232626 & +13 & 8571 \\
\hline I.R.crackMax & 35.9 & 825 & 289. & 289 & 333 & 959 & 13 & 4768 \\
\hline O.R.crackMir & 77.03 & 55 & 23 & $74 C$ & 873 & 1.74 & +14 & 7046 \\
\hline O.R.C & 86.2 & 16 & 92 & 413 & 307 & 1159 & +13 & 04503 \\
\hline Ballc & 27.8 & & $14 \mathrm{~s}$ & & 003 & & +011 & 5209 \\
\hline Ball & 42.9041085 & & & & $1.65 E+004$ & & $9.30 \mathrm{E}+011$ & $5.24 \mathrm{C}$ \\
\hline
\end{tabular}
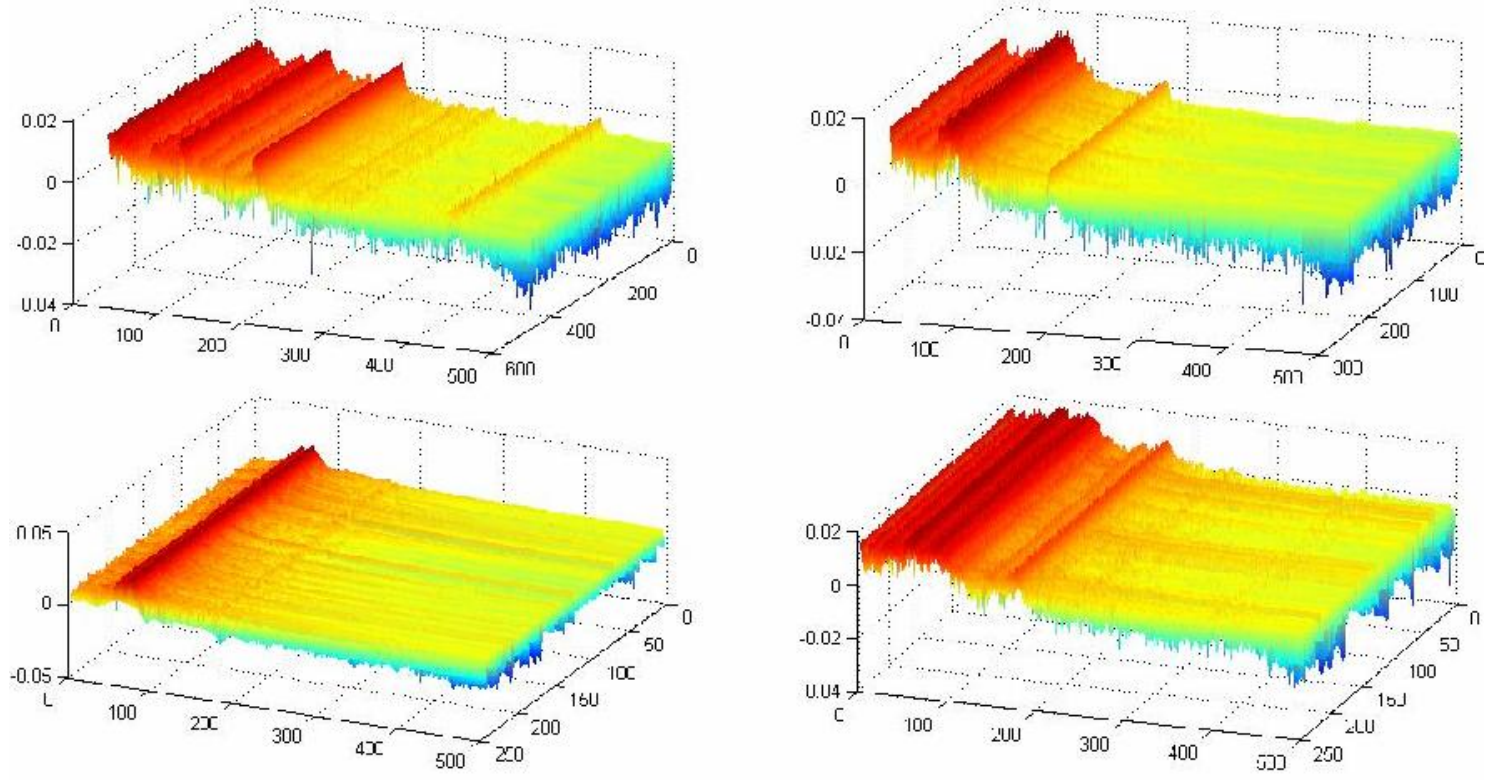

Figure 8. STFT of Raw signals 


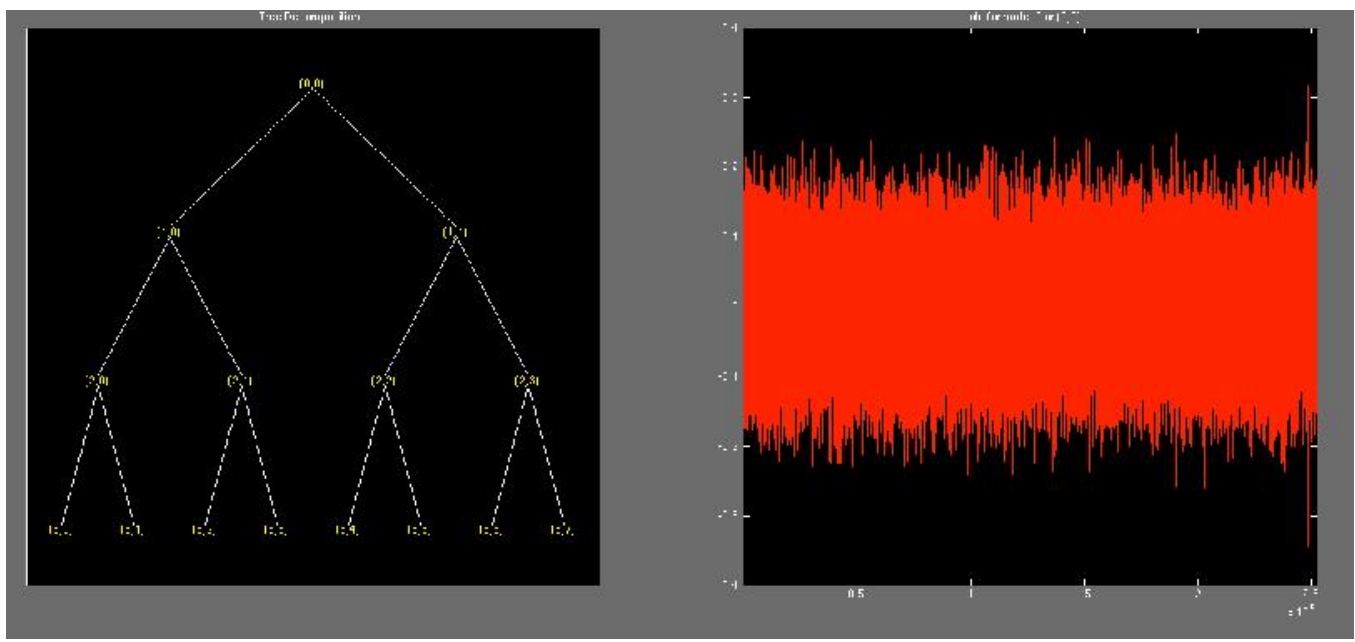

Figure 9. Wavelet Packet Decomposition Tree in Matlab

\subsection{9 \\ $-9.578348898$ \\ 4.968046457 \\ 8137.982076 \\ 8428.680131 \\ 270938030.8 \\ $-1.88826 \mathrm{E}+14$}

-3.075082489
-0.471171635
40.04846746
-2510.096179
25212.54777
478669989.8
$-1.92708 \mathrm{E}+14$

Table 5. Output for frequency domain features

$\begin{array}{rr}-0.046836224 & 0.382966626 \\ 0.396999713 & -2.512513555 \\ 0.414294625 & -1.788527578 \\ 446.7337769 & -2742.143509 \\ -5587.478209 & 27782.09485 \\ 690376688.4 & -2642907701 \\ 6.94404 \mathrm{E}+14 & 2.52886 \mathrm{E}+14\end{array}$

$\begin{array}{rr}-0.82188709 & 2.932806798 \\ 0.991952588 & 7.986779056 \\ 16.546493 & -3.730031348 \\ -1999.891375 & -4114.781394 \\ 21649.30376 & 21828.76464 \\ 469346296.9 & 471086212.8 \\ -1.92662 \mathrm{E}+14 & -1.92683 \mathrm{E}+14\end{array}$

-2.286455902
2.993133163
-4.717912367
11123.07811
-4522.53734
-70630248.43
$-1.72692 \mathrm{E}+14$
$-0.046836224$

0.396999713

0.414294625

446.7337769

$-5587.478209$

690376688.4

$6.94404 \mathrm{E}+14$

Table 6. Output for frequency domain features

$\begin{array}{lll}0.122527158 & 0.131692234 & 0.119004465\end{array}$ $\begin{array}{lll}0.032969818 & 0.031558319 & 0.033076664\end{array}$

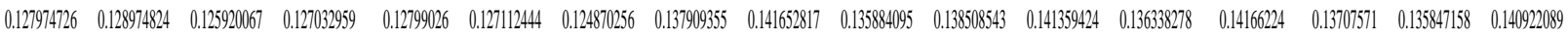

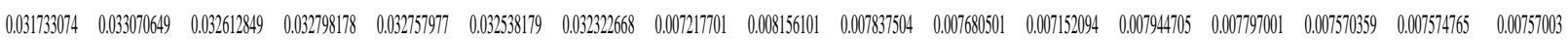

$\begin{array}{rrr}0.122527158 & 0.085073828 & 0.006396437 \\ 0.131692234 & 0.077582523 & 0.005892048 \\ 0.119904465 & 0.087569727 & 0.006098771 \\ 0.127974726 & 0.080759883 & 0.006040159 \\ 0.128974824 & 0.078343392 & 0.005942993 \\ 0.125920067 & 0.081857445 & 0.006199972 \\ 0.127032959 & 0.08100016 & 0.005690814 \\ 0.12799026 & 0.079392699 & 0.006374685 \\ 0.127112444 & 0.081124059 & 0.006055545 \\ 0.124870256 & 0.083222085 & 0.006223319 \\ 0.128112953 & 0.080506262 & 0.006013139 \\ 0.128297322 & 0.078861908 & 0.00630215 \\ 0.125325719 & 0.083874496 & 0.006006114 \\ 0.123923021 & 0.085587421 & 0.005806481 \\ 0.123915505 & 0.085733332 & 0.005825487 \\ 0.12990445 & 0.0785098 & 0.006090417 \\ 0.129924259 & 0.080184339 & 0.005538605 \\ 0.118582301 & 0.090196461 & 0.005885391 \\ 0.132407995 & 0.078522455 & 0.005826094 \\ 0.127112192 & 0.081271877 & \cap \text { ก } 5087871\end{array}$

Table 7. Energy ratio-Normal

\begin{tabular}{|c|c|c|c|c|}
\hline 0.0329698 & 4. & 0.000382887 & 0.00087141 & 0.002453876 \\
\hline 0.031558319 & 3.97341309611524 & 0.000388523 & 0.000773082 & 0.002452956 \\
\hline 0.033076664 & 3.85502507964842 & 0.000376517 & 0.000823712 & 0.002421776 \\
\hline 0.031733074 & 4.19803642170569 & 0.000372462 & 0.000766034 & 0.002405773 \\
\hline 0.033070649 & 3.75368194790226 & 0.000341562 & 0.000835148 & 0.00249705 \\
\hline 0.032612849 & 4.18124465744954 & 0.000386093 & 0.000826552 & 0.002473283 \\
\hline 0.032798178 & 3.65316547857871 , & 0.000369982 & 0.000781807 & 0.002353203 \\
\hline 0.032757977 & 4.29914675852748 & 0.000406515 & 0.000857567 & 0.002500443 \\
\hline 0.032538179 & 3.69359749626754 & 0.000370439 & 0.000802989 & 0.002436924 \\
\hline 0.032322668 & 4.05072056072017 ، & 0.000375729 & 0.000878884 & 0.002403483 \\
\hline 0.031815692 & 3.72347088938784 & 0.000376282 & 0.000797724 & 0.002418588 \\
\hline 0.033227962 & 4.10244522883351 , & 0.000411222 & 0.000873412 & 0.002524756 \\
\hline 0.031664096 & 4.05983992325716 & 0.000372733 & 0.000827813 & 0.002326891 \\
\hline 0.031584502 & 4.22314044699101 & 0.000392526 & 0.000769972 & 0.002316759 \\
\hline 0.031641829 & 3.77788618778836 & 0.000379702 & 0.000787006 & 0.002288128 \\
\hline 0.031991406 & 4.55298713121565 & 0.000428188 & 0.000825367 & 0.002481529 \\
\hline 0.031140152 & 3.97040573545211 , & 0.000391358 & 0.000751381 & 0.002279664 \\
\hline 0.032230744 & 3.75044344959924 & 0.00038755 & 0.00081654 & 0.002357159 \\
\hline 0.029975125 & 3.34526977403635 & 0.000323964 & 0.000757712 & 0.002265323 \\
\hline$n \cap 2100 k 562$ & 271111187750761. & ก กกก278167 & ก กกกอกวา77 & 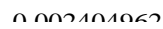 \\
\hline
\end{tabular}


Table 8. Ball fault

$\begin{array}{rrr}0.137909355 & 0.10352466 & 0.001099761 \\ 0.141652817 & 0.098785764 & 0.001133742 \\ 0.135884095 & 0.10500081 & 0.001090706 \\ 0.138508543 & 0.102421987 & 0.001137074 \\ 0.141359424 & 0.100333816 & 0.001061247 \\ 0.136338278 & 0.106313294 & 0.001095648 \\ 0.14166224 & 0.099922532 & 0.001154889 \\ 0.13707571 & 0.104556467 & 0.001090045 \\ 0.135847158 & 0.105795737 & 0.001062543 \\ 0.140922089 & 0.100378271 & 0.001141415 \\ 0.1390979 & 0.101792629 & 0.001137191 \\ 0.137330344 & 0.103460916 & 0.001047212 \\ 0.140914213 & 0.099627845 & 0.001101029 \\ 0.131666935 & 0.109303885 & 0.001043992 \\ 0.139721648 & 0.101875943 & 0.001047382 \\ 0.1354692 & 0.106480895 & 0.001003171\end{array}$

0.0072177017 .2256006076447916 .98363709787668 ، 5.09556866219134 $0.0081561016 .70040107946022,6.89125820109429,5.52221516329903$ । $0.0078375046 .86839338560677,7.05021959853611$ 15.10656677740831 $0.0076805016 .6559462253096216 .73778720069972,5.94886578685309$, 0.0071520948 .3705792703898217 .1686504799399814 .53727236813076 $0.0079447059 .43844721657841,7.1250011628079615 .62105739025975$ 0.0077970018 .85450668122178 17.19992742672873,6.08776373987953 $0.0075703597 .9417834522323917 .27101443292945 ; 5.56345591706923$ $0.0075747658 .5170544895485017 .14521442684629 ، 5.42382225316695$, $0.007570037 .2076182674502317 .33076344975837,5.35234199485244$ । $0.007972541 \quad 6.79 \mathrm{E}-06 \quad 6.9402048652141614 .61492869152757$, $0.0079756717 .48566927518148,6.52601047269533,4.52689789825708$ $0.0082215317 .40377658388247,6.77228568776042,4.52417709968597$, $0.0078932387 .4731350419794817 .27826541000501,5.10317349533309$ $0.0071286437 .32948589287757,6.9048324646383514 .52945298959637$, 0.0069592897 .3619569525732216 .8252558610059615 .03291163404162
0.000137255

0.000152541

0.000144314

0.000142381

0.000154237

0.000155142

0.000154009

0.000141637

0.000142681

0.00014746

0.000147995

0.000145661

0.000136295

0.00014944

0.000138325

0.000149027
0.999815

0.99981

0.999805

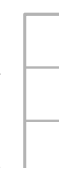

0.136359588

0.127676034

0.142205462

0.129250018

0.136119051

0.126477033

0.137315292

0.140646479

0.140483132

0.141648829

0.146269212

0.128086273

0.138079352

0.139998322

0.124778813

0.137205885

0.148165606

ก 124604588
0.109931542

0.119457153

0.104939519

0.118031069

0.11070007

0.120531955

0.11005855

0.106198686

0.106063723

0.104773344

0.100405858

0.118178621

0.108482875

0.106184792

0.121540072

0.109745023

0.099947978

ก 111080107

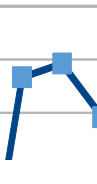

0.001316664

0.001218883

0.001351828

0.001217609

0.001281083

0.00129041

0.001235278

0.001306706

0.001233856

0.001311949

0.001247935

0.001396964

0.001380209

0.001275073

0.001235434

0.001316681

0.001351799

ก กก1วก18ว7

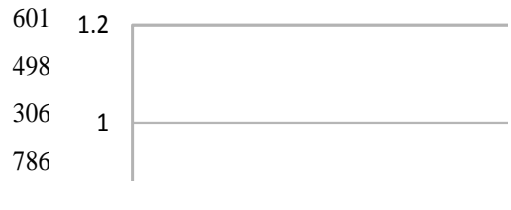

Table 9. Inner race fault

0.0024880377 .96290905663794 ، 2.13776367537029 1 1.64165528228629 ، 3.41249930376856 । $0.0024873459 .32602237392842 ، 2.20281446992638$ 1.89441011398836r 3.93034401243899 । $0.0023683977 .82290181703301 ، 2.24785950107614$ i 1.79609213366565 i 3.69572984603224 । $0.0025642018 .95292451657496 r 2.25491527257360$ 1.78366722438522، 3.40483173616672 $0.00248617 .96211262162183 ، 2.29972915324107$ 1.80681990678811،3.87223140248543 0.0024751878 .95828158109864 2.38428846284281، 2.46908091187886، 3.90370145483479 । $0.0024617358 .25998513008871 ، 2.20024910713028$ 1.77823544375094، 3.97328141283838 । $0.0023707227 .92188860776892 ، 2.19410788310657$ 1.62776991473039،3.42283120090289 0.0024020887 .7562183401827012 .18502401048131 1.76429314391108، 3.78137274052676 । $0.0024352547 .87076373931425 ، 2.34439605762138$ 1.65400090677692،3.67611672765952 $0.002444421 \quad 7.97 \mathrm{E}-06 \quad 2.3545876235715211 .7997735072483213 .75158426476863$ । $0.0025713328 .99716301926945 ، 2.53848396020348$ 1.84665058049196i 3.97795931275413 । 0.0024277287 .63839996016290 2.33586180672249 1.60633056082220، 3.63802979160129 । $0.0025313518 .63315179697805 ، 2.32006424748736$ 1.73005058327221،3.64480736623165 $0.0025747638 .91842463423631 ، 2.35112526398864$ 1 1.89268405167601، 4.24119315008329 । 0.0024135848 .1218775205726912 .36545452064621 1.83479290130603، 3.85600062207490 । 0.0022969617 .05547471985839 ، 2.45451715979788 2.14222827683232، 3.97460747088004 ।

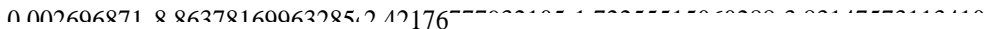

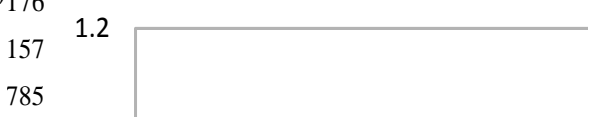




\begin{tabular}{|c|c|c|c|}
\hline 0.099042638 & 0.145502099 & 0.001408388 & 0.0040428491 .06006588081974 ، $2.69294688111643 ، 3.13348325666125 ، 6.99089843181154$ \\
\hline 0.078970137 & 0.167044826 & 0.001590577 & $0.0038861751 .09886353760810,2.69564657046670 ، 2.95755555586056 ، 6.74097405213235$ r \\
\hline 0.10108304 & 0.143730974 & 0.00181964 & $0.0036930369 .48323538884373 ، 2.80691953288068$ ، 2.88642038201682 ; 7.59505219124349 ( \\
\hline 0.097056283 & 0.147567499 & 0.001440932 & $0.004003081 .06684900580037 ، 2.70188983334259 ، 2.55682241588316$ 6.45856039501392 \\
\hline 0.077129681 & 0.167721082 & 0.001510177 & $0.0040162481 .17171266472531,2.80544764341548 ، 8.75714565674446$ 8.21793788898269 \\
\hline 0.099740731 & 0.145910301 & 0.001810613 & $0.0036982039 .63461145741840 ، 2.81286834124851 ، 3.59632832712731,6.29875865781657$ ، \\
\hline 0.105705874 & 0.138785362 & 0.001616359 & $0.0038698739 .62261388796554,2.82486070628119 ، 3.72987085033520 ، 6.63710767804452$ \\
\hline 0.071920517 & 0.172837914 & 0.00165981 & $0.0038398861 .09585402796761,2.66723914961541 ، 5.43510008698121,8.77844733675693$ \\
\hline 0.094996424 & 0.149561006 & 0.001721767 & 0.0038748689 .94985892505244 ، $2.79210839029442 ، 3.23724054679831$, 8.67259974974561 \\
\hline 0.074893011 & 0.16961275 & 0.001609437 & $0.0038762391 .09290956948210 ، 2.63030019877577 ، 3.19759386947489$,9.55430700525330 \\
\hline 0.096735202 & 0.147677981 & 0.001671255 & $0.0039273689 .92574105698957 ، 2.74436114714962 ، 3.70392242419794$ \9.50004557133015 \\
\hline 0.078549053 & 0.165880997 & 0.001620016 & $0.0039772171 .08519146949689 ، 2.69332641163090 ، 2.90150595012630$ 9.24417603850937، \\
\hline 0.097236581 & 0.148215854 & 0.001734875 & $0.0039526221 .07916754155880 ، 3.37138512248984$ ، 1.22792527817699 •1.10256816472904 \\
\hline 0.090098675 & 0.15850427 & 0.001651202 & $0.0038802411 .05086347349774,2.64419646348692$ ، 3.22316967304925 ;.83986228132879 \\
\hline 0.095818274 & 0.1486947 & 0.001689082 & $0.0038201189 .89758658192955,2.65402073992566 ، 2.58589837492600$ 7.80055464982141 \\
\hline 0.092798462 & 0.151898413 & 0.001560302 & $0.0039019111 .08718748314933 ; 2.80665077656808 ، 5.67902907812535 ; 8.10256281386038$ \\
\hline 0.087186273 & 0.15819036 & 0.001621389 & $0.0038234341 .06007295730726 ، 2.63953269206887 ، 2.46786957868394$ ، 6.28571059597236 \\
\hline m..nnm. & $\cdots \cdots \cdots$ & mman & 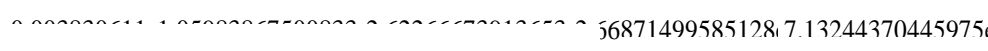 \\
\hline 0.99987 & & & $23 \quad 1.2$ \\
\hline
\end{tabular}

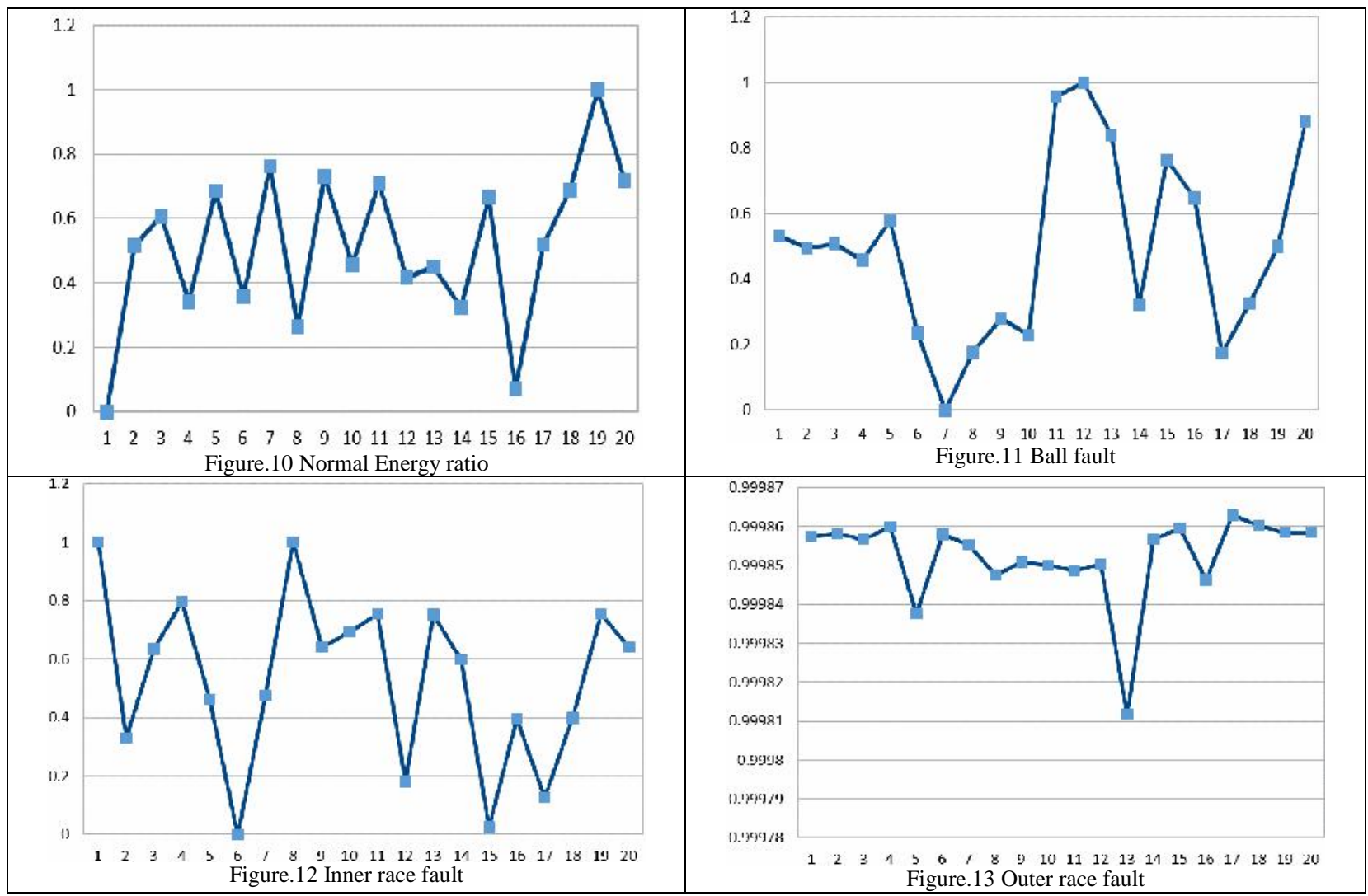


Table 11. Training input for SVM

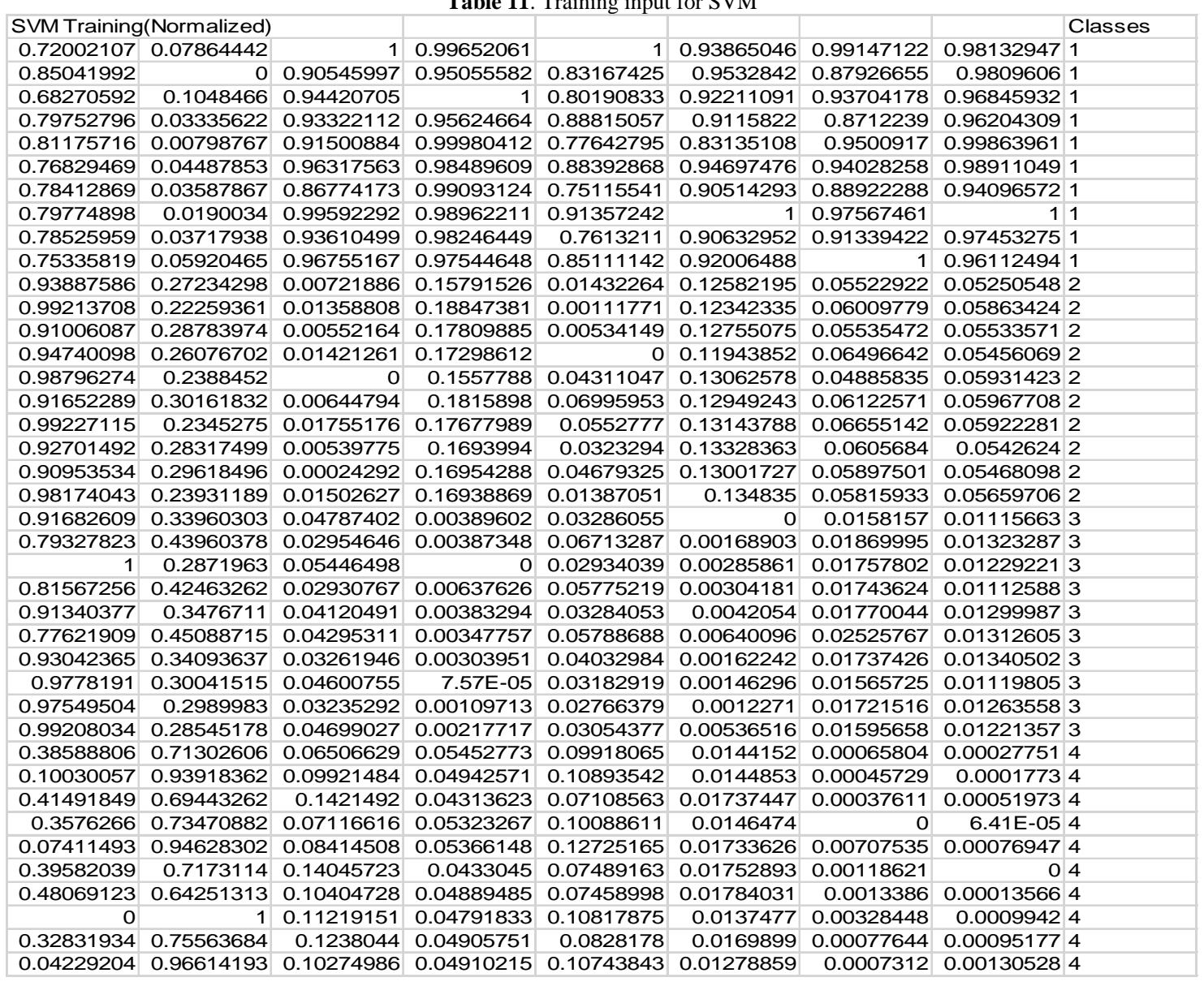


Table 12. Checking input for SVM

SVM Checking (Normalized)

\begin{tabular}{|l|l|l|l|l|l|l|l|l|}
0.72632806 & 0.02191435 & 0.94545912 & 0.95434128 & 0.78587532 & 0.87248946 & 0.91309661 & 0.95784425 \\
\hline
\end{tabular} \begin{tabular}{|r|r|r|r|r|r|r|r|r|}
\hline 0.72884427 & 0.00386495 & 1 & 1 & 0.88370072 & 0.95832189 & 1 & 11 \\
\hline
\end{tabular} \begin{tabular}{|l|l|l|l|l|l|l|l|l|l|}
\hline 0.68828882 & 0.05888608 & 0.94413339 & 0.94944017 & 0.87270293 & 0.8637711 & 0.94764417 & 0.921434451 \\
\hline
\end{tabular} \begin{tabular}{|l|l|l|l|l|l|l|l|l|l|}
\hline 0.66914527 & 0.07768816 & 0.90645953 & 0.9468669 & 0.91485602 & 0.91239392 & 0.88123234 & 0.917411371 \\
\hline
\end{tabular} \begin{tabular}{|l|l|l|l|l|l|l|l|l|l|}
0.66904269 & 0.07928977 & 0.91004626 & 0.94872028 & 0.79992165 & 0.88089091 & 0.90079042 & 0.90604297 & 1
\end{tabular} \begin{tabular}{|l|r|r|r|r|r|r|r|}
\hline 0.75077782 & 0 & 0.96004268 & 0.96002212 & 1 & 1 & 0.94483573 & 0.98283601 \\
\hline
\end{tabular} \begin{tabular}{|l|l|l|l|l|l|l|l|l|l|}
0.75104816 & 0.01838073 & 0.85590715 & 0.93250105 & 0.84961711 & 0.90952465 & 0.85988653 & 0.90268221 \\
\hline
\end{tabular} \begin{tabular}{|r|r|r|r|r|r|r|r|r|}
0.5962569 & 0.12827972 & 0.92135108 & 0.96775992 & 0.7928378 & 0.90017005 & 0.93470075 & 0.933452861 \\
\hline
\end{tabular} \begin{tabular}{|l|l|l|l|l|l|l|l|l|l|}
\hline 0.78494537 & 0.00013891 & 0.91016081 & 0.8948357 & 0.68824952 & 0.74396681 & 0.86715566 & 0.896987871 \\
\hline
\end{tabular} \begin{tabular}{|l|l|l|l|l|l|l|l|l|l|}
\hline 0.71267001 & 0.0308999 & 0.93974764 & 0.96018884 & 0.78268507 & 0.87785705 & 0.91889836 & 0.952433821 \\
\hline
\end{tabular} \begin{tabular}{|l|l|l|l|l|l|l|r|r|}
\hline 0.87624697 & 0.25556614 & 0.02529166 & 0.18349164 & $0.00 \mathrm{E}+00$ & 0.11861843 & 0.0501541 & 0.0562682 \\
\hline
\end{tabular} \begin{tabular}{|l|l|l|l|l|l|l|l|l|}
\hline 0.85212395 & 0.27387824 & 0.00831122 & 0.18359283 & 0.01795745 & 0.10844346 & 0.04914335 & 0.055341252 \\
\hline
\end{tabular} \begin{tabular}{|l|l|l|l|l|l|l|l|l|}
0.9010354 & 0.23180418 & 0.01846733 & 0.19154149 & 0.01584354 & 0.11449338 & 0.04911211 & 0.051622322 \\
\hline
\end{tabular} \begin{tabular}{|l|l|l|l|l|l|l|l|l|}
\hline 0.77483163 & 0.33801414 & 0.00770356 & 0.18092777 & 0.0176339 & 0.12692311 & 0.05576002 & 0.056841762 \\
\hline
\end{tabular} \begin{tabular}{|l|l|l|l|l|l|l|l|l|l|}
0.88475967 & 0.25648064 & 0.00834331 & 0.15620839 & 0.01392586 & 0.11774948 & 0.04917268 & 0.052428372 \\
\hline
\end{tabular} \begin{tabular}{|l|l|l|l|l|l|l|l|l|l|}
\hline 0.82672367 & 0.30702732 & 0 & 0.15073318 & 0.01476404 & 0.11579463 & 0.05495329 & 0.056677772 \\
\hline
\end{tabular} \begin{tabular}{|l|l|l|l|l|l|l|l|l|}
\hline 0.90536369 & 0.24052693 & 0.00382432 & 0.1605005 & 0.02192979 & 0.12865738 & 0.05945597 & 0.052558612 \\
\hline
\end{tabular} \begin{tabular}{|l|l|l|l|l|l|l|l|l|l|}
\hline 0.81006091 & 0.32965398 & 0.01007553 & 0.16463247 & 0.05803845 & 0.12385548 & 0.05576322 & 0.05444152 \\
\hline
\end{tabular} \begin{tabular}{|l|l|l|l|l|l|l|l|l|l|}
\hline 0.86437441 & 0.27141997 & 0.00982604 & 0.16034253 & 0.02259756 & 0.13223146 & 0.04538201 & 0.055341652 \\
\hline
\end{tabular} \begin{tabular}{|l|l|l|l|l|l|l|l|l|l|}
\hline 0.90415751 & 0.24690576 & 0.00196113 & 0.15889622 & 0.01011891 & 0.11361013 & 0.04902006 & 0.060043712 \\
\hline
\end{tabular} \begin{tabular}{|r|r|r|r|r|r|r|r|r|}
\hline 0.97411865 & 0.24034412 & 0.04619079 & 0.00476739 & $3.05 \mathrm{E}-02$ & 0.00596969 & 0.01783107 & 0.012400443 \\
\hline
\end{tabular} \begin{tabular}{|r|r|r|r|r|r|r|r|r|}
\hline 0.72596394 & 0.4354285 & 0.07431488 & 0.00887042 & 0.05697394 & 0.01048722 & 0.0183693 & 0.01329933 \\
\hline
\end{tabular} \begin{tabular}{|l|l|l|l|l|l|l|l|}
\hline 0.86234616 & 0.32900224 & 0.07115295 & 0.0042277 & 0.02189992 & 0.00550967 & 0.01561 & 0.011949553 \\
\hline
\end{tabular} \begin{tabular}{|l|l|l|l|l|l|l|l|l|}
\hline 0.88853563 & 0.30377712 & 0.05131215 & 0.00757783 & 0.04757764 & 0.0051216 & 0.01703053 & 0.011976463 \\
\hline
\end{tabular} \begin{tabular}{|l|l|l|l|l|l|l|l|l|l|}
0.68082483 & 0.47232578 & 0.04383165 & 0.00898135 & 0.05494145 & 0.00588463 & 0.01889785 & 0.014344513 \\
\hline
\end{tabular} \begin{tabular}{|l|l|l|l|l|l|l|l|l|l|l|}
\hline 0.85042537 & 0.34285633 & 0.05916423 & 0.00377042 & 0.03438002 & 0.00623664 & 0.01823316 & 0.012815043 \\
\hline
\end{tabular} \begin{tabular}{|l|l|l|l|l|l|l|l|l|l|}
1 & 0.23531815 & 0.06579154 & 0 & 0.00685275 & 0.00842452 & 0.02176306 & 0.013285993 \\
\hline
\end{tabular} \begin{tabular}{|l|l|l|l|l|l|l|l|l|}
\hline 0.81615203 & 0.36738994 & 0.03748949 & 0.0129291 & 0.05353094 & 0.00762001 & 0.01694446 & 0.012717663 \\
\hline
\end{tabular} \begin{tabular}{|l|l|l|l|l|l|l|l|l|}
\hline 0.74646496 & 0.42019637 & 0.05453428 & 0.00228441 & 0.03849979 & 0 & 0.01571368 & 0.012521733 \\
\hline
\end{tabular} \begin{tabular}{|r|r|r|r|r|r|r|r|r|}
\hline 0.74058102 & 0.42451711 & 0.06511613 & 0.00124118 & 0.02976521 & 0.00408461 & 0.014584 & 0.013024733 \\
\hline
\end{tabular} \begin{tabular}{|l|r|r|r|r|r|r|r|r|}
\hline 0 & 1 & 0.11441185 & 0.0510581 & 0.1068433 & 0.01274275 & 0.00083785 & 0.001297854 \\
\hline
\end{tabular} \begin{tabular}{|r|r|r|r|r|r|r|r|}
\hline 0.29809496 & 0.75923097 & 0.12607787 & 0.0527111 & 0.08094351 & 0.01554473 & 0.00141921 & 0.00127634 \\
\hline
\end{tabular} \begin{tabular}{|l|l|l|l|l|l|l|l|l|l|}
\hline 0.04989644 & 0.95903807 & 0.11640827 & 0.05432272 & 0.10485101 & 0.01429103 & 0.00049789 & 0.001174714 \\
\hline
\end{tabular} \begin{tabular}{|l|l|l|l|l|l|l|l|l|l|}
\hline 0.30493761 & 0.76513498 & 0.13808396 & 0.05352756 & 0.10329604 & 0.03094799 & 0.01126523 & 0.001882084 \\
\hline
\end{tabular} \begin{tabular}{|l|l|l|l|l|l|l|l|l|}
0.20752184 & 0.87806674 & 0.12229356 & 0.05118748 & 0.09598986 & 0.01308412 & 0.00086722 & 0.00061714 \\
\hline
\end{tabular} \begin{tabular}{|l|l|l|l|l|l|l|l|l|l|}
\hline 0.28558103 & 0.77039108 & 0.12944211 & 0.0492437 & 0.08021675 & 0.01332546 & 0.00013552 & 0.000601494 \\
\hline
\end{tabular} \begin{tabular}{|l|l|l|l|l|l|l|l|l|l|}
0.24436764 & 0.80555693 & 0.10513931 & 0.05188807 & 0.10536625 & 0.01707492 & 0.00368699 & 0.000721414 \\
\hline
\end{tabular} \begin{tabular}{|r|r|r|r|r|r|r|r|}
0.16777435 & 0.87462107 & 0.11666738 & 0.04935091 & 0.09836712 & 0.01296955 & 0 & 04 \\
\hline
\end{tabular} \begin{tabular}{|l|l|l|l|l|l|l|l|l|l|}
\hline 0.15306504 & 0.87718567 & 0.11361566 & 0.04958294 & 0.09830664 & 0.01255523 & 0.00023061 & 0.000336214 \\
\hline
\end{tabular} \begin{tabular}{|l|l|l|l|l|l|l|l|l|l|}
\hline 0.25551257 & 0.80472706 & 0.10964773 & 0.05048986 & 0.09366604 & 0.01387219 & 0.00087828 & 0.000267214 \\
\hline
\end{tabular} \begin{tabular}{|l|l|l|l|l|l|l|l|l|}
0.2427171 & 0.80696899 & 0.12803146 & 0.04942756 & 0.08684275 & 0.01304779 & 0.00026636 & 0.000708774 \\
\hline
\end{tabular}

Table 13. Checking input for ANFIS

\begin{tabular}{|c|c|c|c|c|}
\hline ER-4 & ER-5 & ACTUAL O/P & PREDICTED O/P & ERROR \\
\hline 0.12811295 & 0.03181569 & 0 & -0.0003 & 0.0003 \\
\hline 0.12829732 & 0.03322796 & 0 & 0.0002 & 0.0002 \\
\hline 0.12532572 & 0.0316641 & 0 & -0.0001 & 0.0001 \\
\hline 0.12392302 & 0.0315845 & 0 & -0.0002 & 0.0002 \\
\hline 0.12391551 & 0.03164183 & 0 & -0.0003 & 0.0003 \\
\hline 0.12990445 & 0.03199141 & 0 & -0.0005 & 0.0005 \\
\hline 0.12992426 & 0.03114015 & 0 & -0.0005 & 0.0005 \\
\hline 0.1185823 & 0.03223074 & 0 & -0.0001 & 0.0001 \\
\hline 0.132408 & 0.02997512 & 0 & -0.0043 & 0.0043 \\
\hline 0.12711219 & 0.03199656 & 0 & -0.0002 & 0.0002 \\
\hline 0.1390979 & 0.00797254 & 0.333333 & 0.3527 & 0.019367 \\
\hline 0.13733034 & 0.00797567 & 0.333333 & 0.3531 & 0.019767 \\
\hline 0.14091421 & 0.00822153 & 0.333333 & 0.3741 & 0.040767 \\
\hline 0.13166693 & 0.00789324 & 0.333333 & 0.3465 & 0.013167 \\
\hline 0.13972165 & 0.00712864 & 0.333333 & 0.3122 & 0.021133 \\
\hline 0.1354692 & 0.00695929 & 0.333333 & 0.3149 & 0.018433 \\
\hline 0.14123136 & 0.0072614 & 0.333333 & 0.3134 & 0.019933 \\
\hline
\end{tabular}


Table 13 (Cont'd). Checking input for ANFIS

\begin{tabular}{|c|c|c|c|c|}
\hline ER-4 & ER-5 & ACTUAL O/P & PREDICTED O/P & ERROR \\
\hline 0.13424828 & 0.00738921 & 0.333333 & 0.3171 & 0.016233 \\
\hline 0.13822797 & 0.00725652 & 0.333333 & 0.3134 & 0.019933 \\
\hline 0.14114298 & 0.00721178 & 0.333333 & 0.3126 & 0.020733 \\
\hline 0.14626921 & 0.00244442 & 0.666667 & 0.6664 & 0.000267 \\
\hline 0.12808627 & 0.00257133 & 0.666667 & 0.7298 & 0.063133 \\
\hline 0.13807935 & 0.00242773 & 0.666667 & 0.6575 & 0.009167 \\
\hline 0.13999832 & 0.00253135 & 0.666667 & 0.7105 & 0.043833 \\
\hline 0.12477881 & 0.00257476 & 0.666667 & 0.7314 & 0.064733 \\
\hline 0.13720589 & 0.00241358 & 0.666667 & 0.6501 & 0.016567 \\
\hline 0.14816561 & 0.00229696 & 0.666667 & 0.585 & 0.081667 \\
\hline 0.13469459 & 0.00269687 & 0.666667 & 0.786 & 0.119333 \\
\hline 0.12958844 & 0.00236762 & 0.666667 & 0.6251 & 0.041567 \\
\hline 0.1291573 & 0.00233535 & 0.666667 & 0.6071 & 0.059567 \\
\hline 0.0967352 & 0.00392737 & 1 & 0.9953 & 0.0047 \\
\hline 0.07854905 & 0.00397722 & 1 & 0.9915 & 0.0085 \\
\hline 0.09723658 & 0.00395262 & 1 & 0.9935 & 0.0065 \\
\hline 0.09009868 & 0.00388024 & 1 & 0.9983 & 0.0017 \\
\hline 0.09581827 & 0.00382012 & 1 & 1.0008 & 0.0008 \\
\hline 0.09279846 & 0.00390191 & 1 & 0.9971 & 0.0029 \\
\hline 0.08718627 & 0.00382343 & 1 & 1.0008 & 0.0008 \\
\hline 0.08610848 & 0.00383061 & 1 & 1.0006 & 0.0006 \\
\hline 0.09361508 & 0.00385866 & 1 & 0.9994 & 0.0006 \\
\hline 0.09267752 & 0.0038258 & 1 & 1.0007 & 0.0007 \\
\hline
\end{tabular}

\section{Mean Absolute Error for selected Combinations:}

$\begin{array}{lll}0.0015 & \text { combo27 } & 0.019\end{array}$

combo83

0.0025

Table 14. Error table for different combination

\begin{tabular}{|c|c|c|c|c|c|c|c|c|}
\hline S.NO & $\mathbf{1}$ & $\mathbf{2}$ & $\mathbf{3}$ & $\mathbf{4}$ & $\mathbf{5}$ & $\mathbf{6}$ & $\mathbf{7}$ & $\mathbf{8}$ \\
\hline 1 & 0 & 0.007436 & 0.008213 & -0.00393 & -0.00129 & -0.00152 & -0.01703 & -0.00211 \\
\hline 2 & 0 & 0 & 0.002467 & -0.00162 & -0.00841 & -0.00702 & -0.01896 & -0.0075 \\
\hline 3 & 0 & 0 & 0 & -0.01195 & 0.014379 & 0.008492 & -0.01058 & 0.002451 \\
\hline 4 & 0 & 0 & 0 & 0 & -0.00077 & 0.004262 & -0.00749 & -0.00578 \\
\hline 5 & 0 & 0 & 0 & 0 & 0 & 0.00707 & -0.01329 & 0.003778 \\
\hline 6 & 0 & 0 & 0 & 0 & 0 & 0 & -0.0283 & -0.00199 \\
\hline 7 & 0 & 0 & 0 & 0 & 0 & 0 & 0 & -0.01463 \\
\hline 8 & 0 & 0 & 0 & 0 & 0 & 0 & 0 & 0 \\
\hline
\end{tabular}

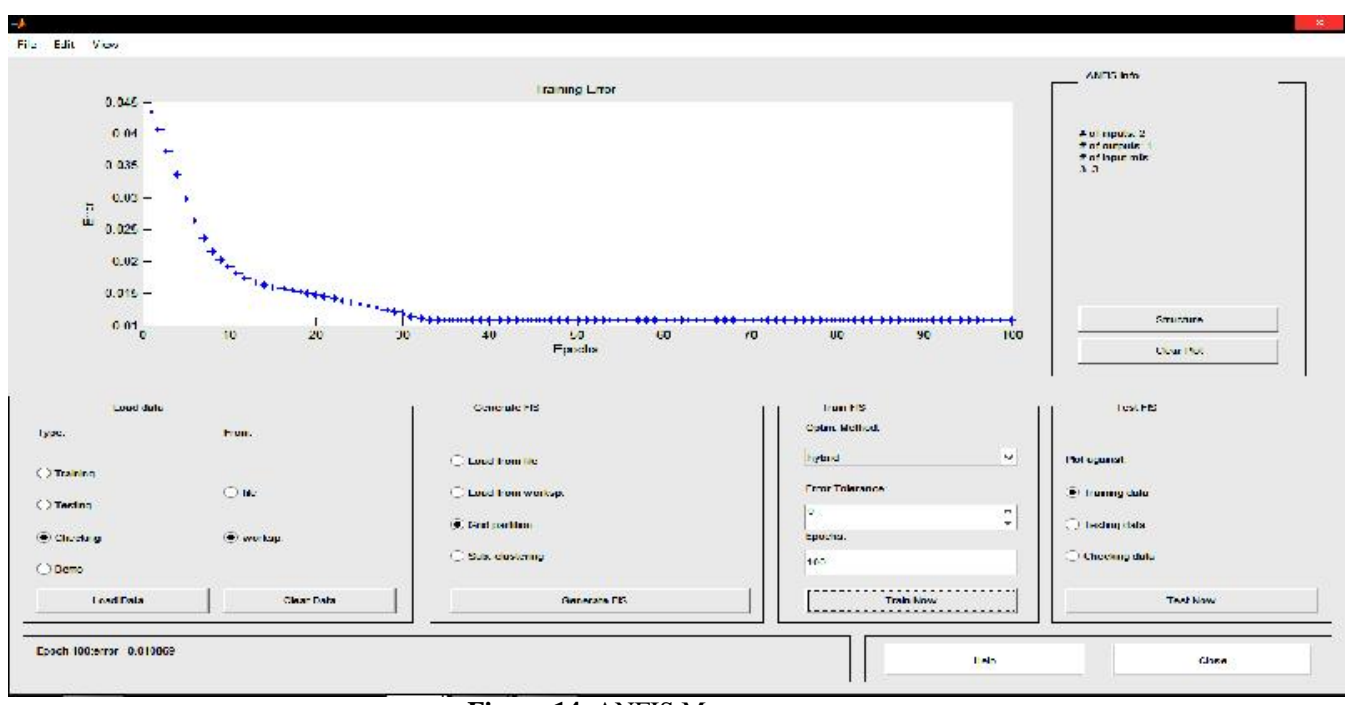

Figure 14. ANFIS Mean square error 


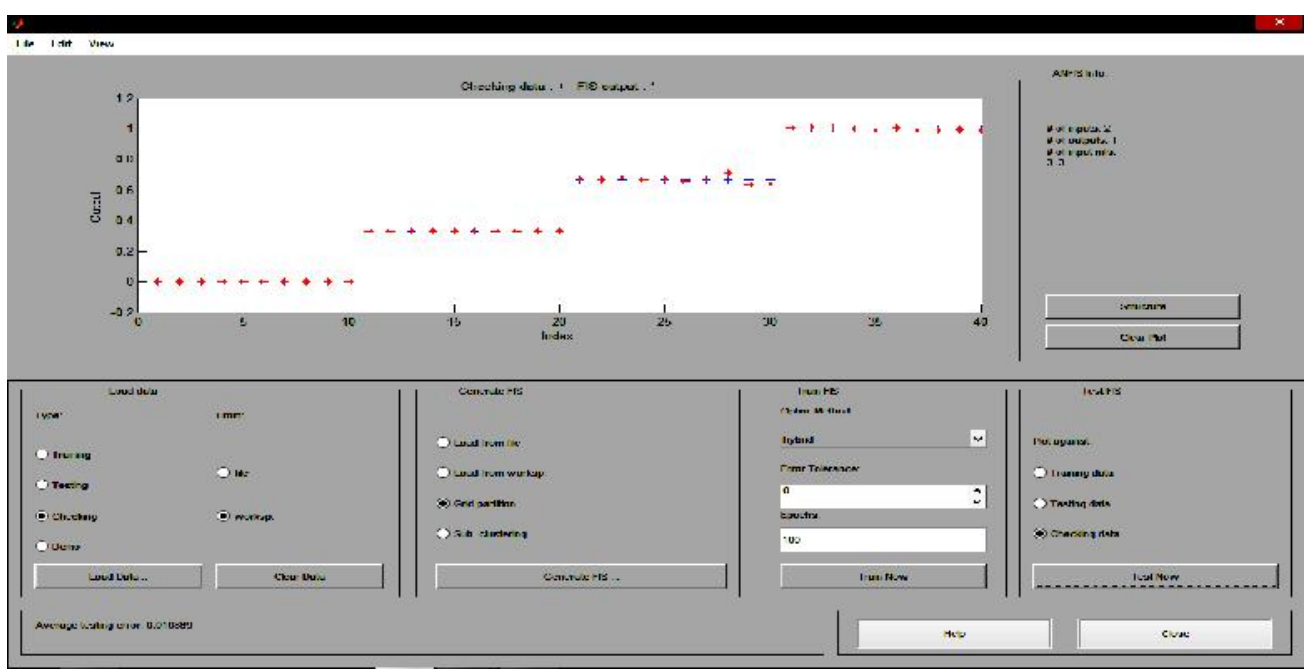

Figure 15. ANFIS classification

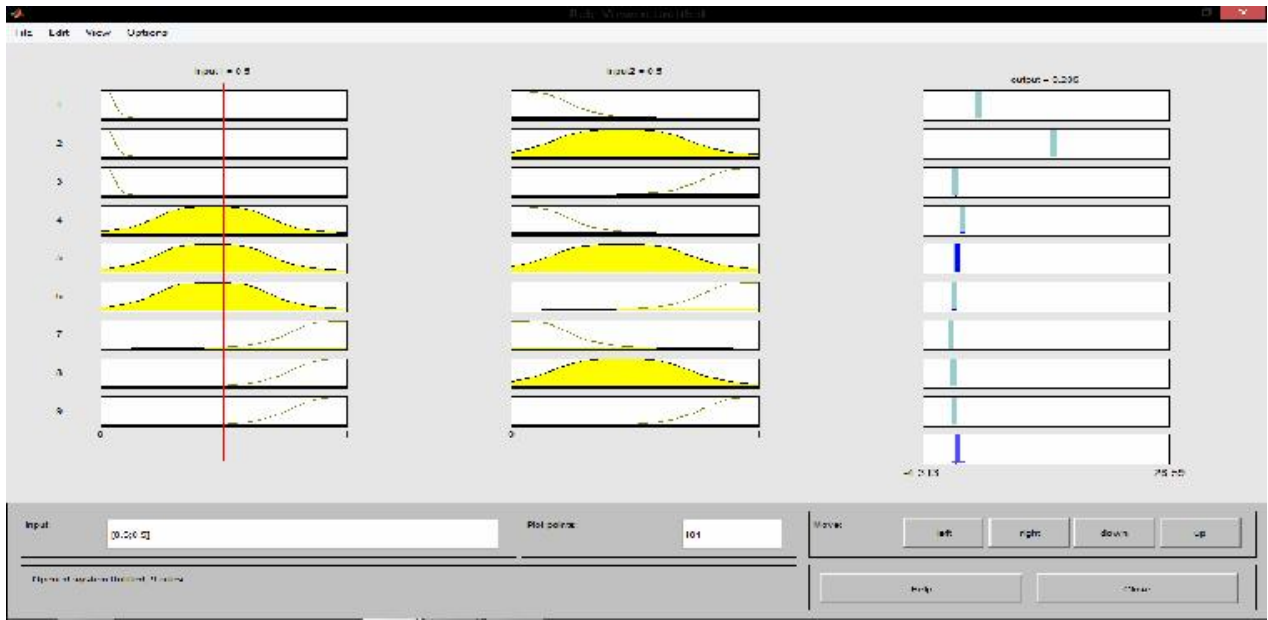

Figure 16. ANFIS rules

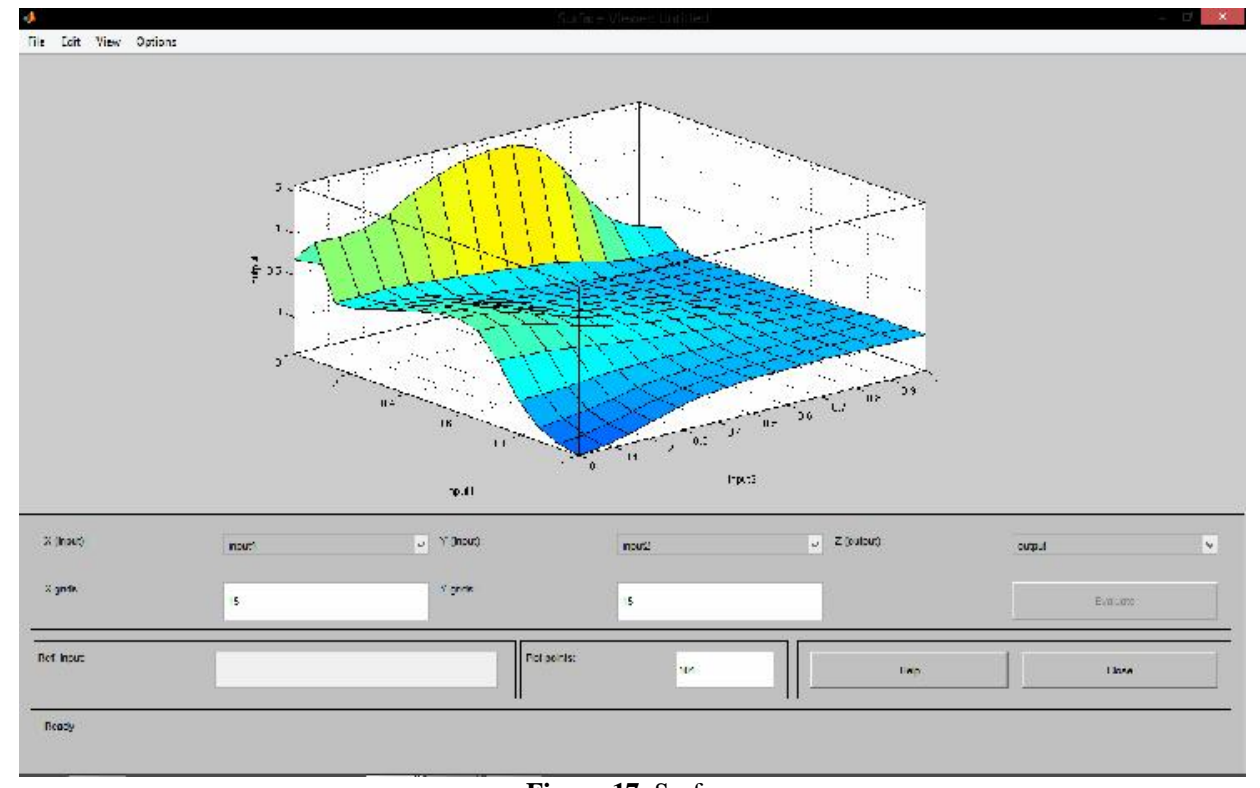

Figure 17. Surface 


\section{Conclusions}

In this paper, a fault identification method has been proposed to identify the type of ball bearing fault. The proposed method is the combination of wavelet decomposition method, Principal component analysis and ANFIS or SVM. ANN and fuzzy based algorithm has been popularly used in the fault identification process. However, the use of SVM for machine condition monitoring and fault diagnosis is still rare. In this work, both conventional ANFIS and SVM techniques are implemented. It is found that SVM technique has higher accuracy compared to ANFIS. The proposed method has been simulated and validated using the vibration data collected from the ball bearing setup. The simulation result shows that the proposed method exactly predicts the type of fault and it has very good accuracy. Some improved version of SVM and ANFIS algorithm can be used to further improve accuracy of prediction is the future work. The proposed method may be extend to fault detection in other mechanical rotating elements

\section{References}

Bhende A.R., Awari G.K. and Untawale S.P.. 2011. Assessment of bearing fault detection using vibration signal analysis. VSRDTNTJ, Vol. 2, No. 5, pp. 2011, 249-261.

Jiang F., Dong L., Dai Q., Nobes D.C., 2018, Using wavelet packet denoising and ANFIS networks based on COSFLA optimization for electrical resistivity imaging inversion, Fuzzy Sets and Systems, Vol. 337, pp. 93-112

Li H., Mei C., Zhou N., Tang Q., Huang Y., 2006, Diagnosis of working conditions of an aluminum reduction cell based on wavelet packets and fuzzy neural network, Chemical Engineering and Processing: Process Intensification, Vol. 45, No. 12, pp. 1074-1080

Liu H., Tian H-Q and Li Y-F. 2015. Comparison of new hybrid FEEMD-MLP, FEEMD-ANFIS, wavelet packet-MLP and wavelet packed-ANFIS for wind speed predictions. Energy Conversion and Management, Vol 89, pp1-11.

Parey A., Singh A., 2019, Gearbox fault diagnosis using acoustic signals, continuous wavelet transform and adaptive neuro-fuzzy inference system, Applied Acoustics, Vol. 147, pp. 133-140

Samanta, B., Al-Balushi, K.R., 2003. Artificial neural network based fault diagnostics of rolling element bearings using time domain features. Mechanical Systems and Signal Processing. Vol. 17, No.2 pp.317-328.

Saimurugan M., Ramachandran K.I., Sugumaran V., Sakthivel N.R., 2011, Multi component fault diagnosis of rotational mechanical system based on decision tree and support vector machine, Expert Systems with Applications, Vol 38, No 4, pp. 3819-3826

Sun W., Chen J, Li J., 2007, Decision tree and PCA-based fault diagnosis of rotating machinery, Mechanical System and Signal Processing, Vol. 21, No.3, pp. 1300-1317.

Zhang Z., Wang Y., Wang K., 2013, Fault diagnosis and prognosis using wavelet packet decomposition, Fourier transform and artificial neural network, Journal of Intelligent Manufacturing; DOI : 10.1007/s 10845-012-0657-2

Zhu X., Zhang Y., Zhu Y., 2012, Intelligent fault diagnosis of rolling bearing based on kernel neighbourhood rough sets and statistical features. Journal of Mechanical Science and Technology. Vol. 26, No.9, 2649-2657

\section{Biographical notes}

Arun R. Pathiran received M.E. and Ph.D. from Madras Institute of Technology, Anna University, India in 2008 and 2014, respectively. He has more than 10 years of teaching and research experience. At present he is working as Associate Professor in Department of Electrical and Electronics Technology, Federal TVET Institute, Ethiopia. His current area of research includes machine learning, neural networks, PID control, model based control. He has published several journal papers in referred international Journals. He also presented research articles in national and international conferences.

K. Erikiananda, currently working as an Associate Professor in Department of Automotive Technology in FTVETI, Addis Ababa-Ethiopia, he has published more than 30 journals and conference papers since 2010. His research area includes titanium alloys, nanotechnology, simulation modeling and analysis. He is a member of International Association of Engineers and Institution of Engineers Malaysia. He is also an Advisory/Editorial board member of IIER, IASTEM, IJMSE, OGCE, IJMEA, and IISEM, reviewer for IJSTM, IJEX and IJMCMR

T. Getachew and Haftom G. Gziabher are of the ${ }^{2 * 3}$ Department of Automotive Technology, Federal Technical and Vocational Education and Training Institute, Addis Ababa, Ethiopia and Department of Electrical Technology, Federal Technical and Vocational Education and Training Institute, Addis Ababa, Ethiopia, respectively

Received January 2019

Accepted March 2019

Final acceptance in revised form March 2019 